Document downloaded from:

http://hdl.handle.net/10251/120358

This paper must be cited as:

Garmendia, M.; Almandoz Berrondo, J.; Arrizabalaga, A.; Arregui De La Cruz, F. (2018). Pressure management and residential consumption reduction. Water Science \& Technology: Water Supply. 19(1):236-244. https://doi.org/10.2166/ws.2018.071

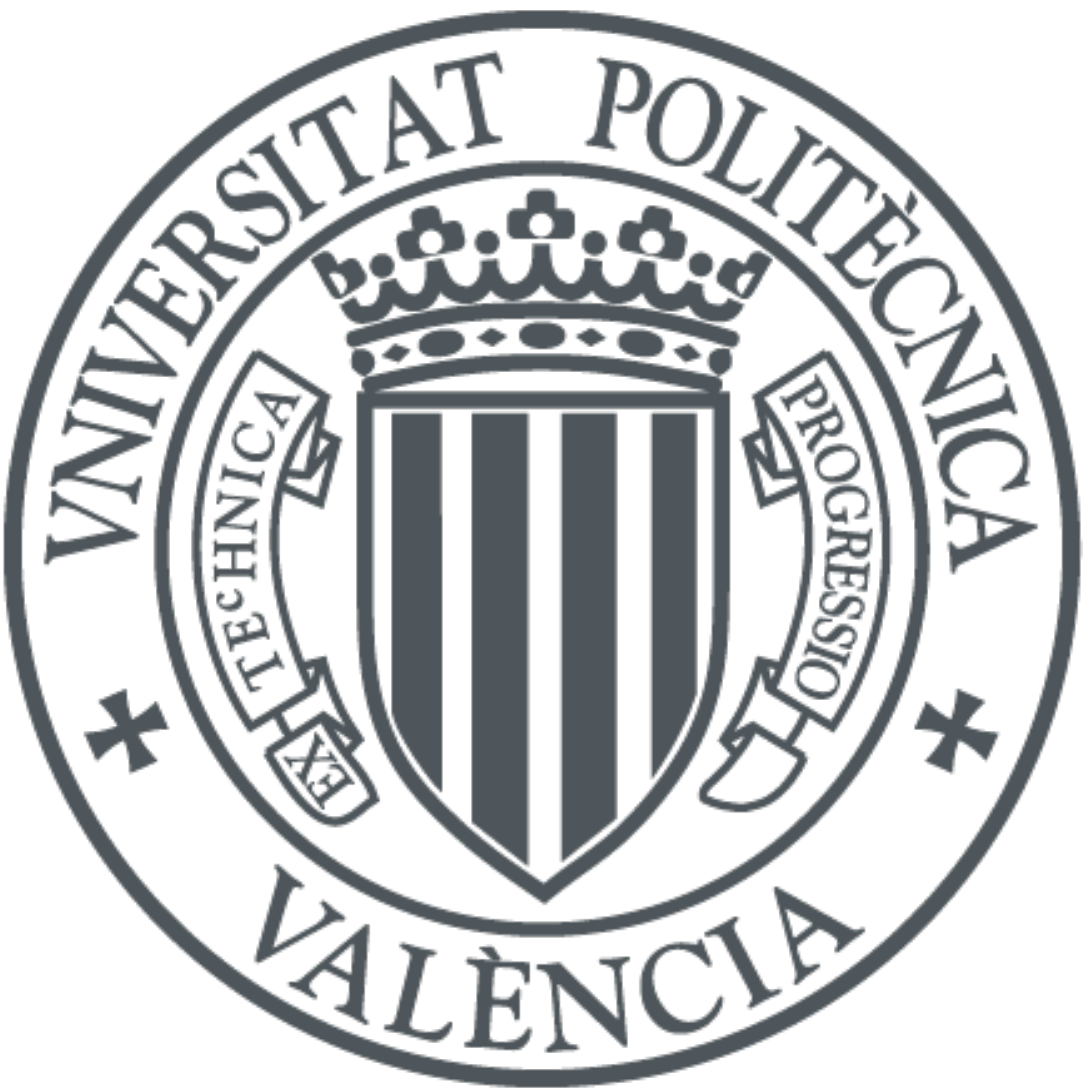

The final publication is available at

http://doi.org/10.2166/ws.2018.071

Copyright IWA Publishing

Additional Information 


\title{
Pressure management and residential consumption reduction
}

\author{
M. Garmendia*, J. Almandoz*, A. Arrizabalaga** and F. Arregui*** \\ * Department of Nuclear Engineering and Fluid Mechanics, University of the Basque Country, Pl Europa 1, 20018, \\ San Sebastian, Spain. \\ (E-mail: maddi.garmendiaa@ehu.eus; jabier.almandoz@ehu.eus) \\ ** Global Omnium, Travesía Ana de Velasco, 2. Pamplona. \\ (E-mail: aarrie@globalomnium.com) \\ ***ITA, Universitat Politècnica de València, Camino de Vera s/n, 46022 Valencia (España) \\ (E-mail:farregui @ita.upv.es)
}

\begin{abstract}
The benefits of applying pressure management in urban water supply networks are well known for more than 10 years. Apart from reducing leakage, it also reduces burst frequency and consumption. However, the reduction of consumption with pressure is an objective that has only been considered a priority in water scarcity scenarios and suffers from a lack of systematic or conclusive studies. This paper analyses the relationship between pressure and consumption in a water distribution network equipped with remote water meter reading. Based on end use breakdowns, the paper estimates the percentage of pressure-dependent consumption. It establishes three different scenarios and assesses the relationship between pressure and consumption by means of the N3 coefficient.
\end{abstract}

\begin{abstract}
Keywords
Pressure management; consumption; water savings; water distribution systems; remote water meter reading
\end{abstract}

\section{PRESSURE MANAGEMENT}

Pressure management goes beyond the strict compliance with the terms and conditions established in the quality of service standards that must be fulfilled by water distribution services. The benefits of applying pressure management in urban water supply networks are well known for decades (GIZ, 2011; Thornton and Lambert, 2005; Lambert, 2001). As a result, the use of pressure reduction techniques has lately been extended in tune with technological advances.

The main benefit, and hence the leading reason motivating the implementation of pressure regulation and management techniques, is leak reduction. Indeed, according to a study carried out by Vicente et al. (2015), leakage management was the main objective in 56 pressure management projects and the only one in $46 \%$ of them. Likewise, Thornton and Lambert (2005) considered pressure management as the pillars of leak management strategies.

However, reducing leakage is not the only outcome derived from pressure management. On the one hand, it also reduces bursts frequency and extends the life of the infrastructure and, on the other, it may lead to a decrease in customers' consumption and therefore water savings within the system (Lambert and Fantozzi, 2010).

While leakage and burst frequency reduction are clearly beneficial factors for utilities, a potential reduction in water consumption implies a decrease in billing. The latter, however, can also be interpreted positively as it can be an effective strategy for water utilities to promote responsible consumption and environmental awareness among customers. Although hardly quantifiable, the social and environmental benefits derived from the reduction of consumption, are essential in a context of water scarcity, climate change and sustainable development. 
Clearly, lowering leakage is the main driver in improving management indicators and other benefits such as reduced bursts frequency and consumption control have not been subjected to as much study. In particular, the reduction of consumption with pressure is a topic that has only been considered a priority in water scarcity scenarios and suffers from a lack of systematic or conclusive studies, especially with regard to the disaggregation of water use components according to the type of consumption (Giustolisi and Walski, 2012).

In the particular case of Spain, a considerable number of public utilities in the North of the country still operate at very high pressures. Doubts on the benefits of pressure management remain, and many utilities are still reluctant to reduce network pressure because of the potential decrease in consumption and revenue that can follow these activities.

This paper analyses the relationship between pressure and residential consumption in a set of similar blocks of houses in a water distribution network located in a village in the North of Spain (Gipuzkoa). The research presented was done in collaboration with the public water utility Gipuzkoako Urak, which made available the required consumption data from the customers as well as the possibility of temporarily modifying the inlet pressure to one District Metered Area (DMA) of its network. For such purpose, a DMA fully equipped with remote water meter reading infrastructure and a Pressure Regulating Valve (PRV) at the inlet was selected. In addition, to better evaluate the decrease in consumption caused by the pressure reduction in the DMA, a number of customers had their own PRV so that their consumption was not affected by variations in network pressure. Consequently, this study, that took place between September 2014 and October 2015, is an opportunity to provide real and reliable consumption data and it can be a valuable reference for future studies.

Results are consistent with the theory that human-based water consumption is not completely volumetric. In other words, is partially or predominantly pressure dependent (Giustolisi and Walski, 2012). Specifically, this paper analyses the relationship between pressure and consumption and determines that tap consumption is around $50 \%$ pressure dependent.

The paper is structured as follows: Section 2 reviews the state of the art on the reduction of consumption derived from pressure management; Section 3 presents the case study and analyses the results; Section 4 develops and discusses the results obtained and Section 5 presents the main conclusions.

\section{RELATIONSHIP BETWEEN PRESSURE AND CONSUMPTION}

Much of the work describing the relationship between pressure and consumption is based on the FAVAD (Fixed and Variable Area Discharge) theory of May (1994). This theory was originally applied to leakage modelling and it came to propose an alternative to the Torricelli Law depending on the type of leakage area (Lambert, 2001; Almandoz et al., 2005). It allowed a more reliable determination of the reduction of leakage rates following a pressure change using a simple Power Law. For the exponent, the International Water Association Water Loss Specialist Group uses the N1 coefficient that depends on several factors: size and shape of the leak hole, pipe material, soil type and flow rate (Thornton and Lambert, 2005).

$$
L_{1} / L_{0}=\left(P_{1} / P_{0}\right)^{N 1}
$$

Since both leakage and consumption can be considered as atmospheric discharges with a given loss coefficient, the FAVAD theory has also been applied, assuming that water consumption partially varies with the available pressure, defining a coefficient N3 (Thornton and Lambert, 2005; Lambert and Fantozzi, 2010). The latter Authors propose a separate analysis of indoor and outdoor 
consumptions and establish different coefficients for each type of water uses (N3i and N3o respectively). For N3i, much smaller values, of approximately 0.04 , are reported than for N3o, for which a value of 0.45 is proposed. These figures are based on several studies carried out in Australia. The extremely low value obtained for the indoor consumption coefficient, N3i, suggests that this portion of residential consumption is fully independent of pressure. This conclusion does not agree with the results extracted from a study carried out in Spain on the end uses of water (Cubillo et al., 2008) showing that $30 \%$ of water consumption was pressure dependent. Other residential end use studies around the world also suggest similar figures (Beal and Steward, 2011; DeOreo and Mayer, 2014)

Lambert and Fantozzi (2010) also propose an equation that allows predicting the percentage of consumption reduction as a function of network pressure taking into account the N3i and N3o coefficients. However, the scarcity of case studies and the variability of the results according to the characteristics of the facilities studied, raise doubts regarding the extrapolation of the results.

Bamezai and Lessick (2003) present an ad hoc study to determine the effects of pressure optimization on consumption. In this study, pressure was reduced during a year to the minimum service pressure standard of the utility in two districts through pressure regulating valves controlled by a SCADA system. Three other neighbourhoods, where network pressure was not reduced, were selected as a control group. Supply pressure in the district under study was lowered from 5.7 to 4.7 bar. As a result, water consumption decreased on average by $1.9 \%$ and by $4.1 \%$ in a specific group of dwellings with large size plots (where outdoor consumption was therefore considerably above the average).

Gomes et al. (2011) establish that the benefit obtained from pressure reduction is a balance between avoiding leakages and unrealized consumption, and propose a model that classifies water demand into pressure dependent and independent components. Likewise, Giustolisi and Walski (2012) demonstrate the need to adequately characterise the pressure dependent and independent parts of water consumption using real data that validates the results of the models.

Pressure independent water uses are those that are not affected by network pressure, since they operate on a fixed volume (so-called volume-based consumption) such us toilet cisterns, washing machines or dishwashers. In any case, a low network pressure will only increase the necessary time to reach the fixed volume. Pressure dependent uses are those that can be affected by variations in pressure, i.e., taps, showers, hoses, etc.

Giustolisi and Walski (2012) classify the types of consumption into four, split between indoor and outdoor uses. The indoor water uses are divided into human-based consumptions, i.e., flows controlled by customers (for example, taps), and volume-based consumptions, i.e., independent of pressure. The outdoor water uses are also classified into uncontrolled orifice-based demands, that is to say, fire protection (hydrants, sprinklers, etc.) and landscape irrigation systems; and into leakagebased demands.

In order to support this type of pressure dependence classification of domestic water consumption, a number of studies on residential water end uses have been conducted to date (Shan et al., 2015; Beal and Steward, 2011; DeOreo and Mayer, 2014; Loh and coghlan, 2003; Vewin, 2016). These end use studies combine household surveys and/or billing data with smart metering devices for improving water consumption monitoring and analysis. In addition, this supplementary information on how customers use water makes it possible to build the relationship between consumption and relevant socio-economic factors. Consequently, disaggregation of residential water end uses is a critical first step in the development and analysis of water policies, such as those related to financial and water- 
saving benefits of efficient water appliances (Willis et al., 2013).

Most authors agree on socio-demographics and property-related factors as well as cultural and psychological factors influencing water consumption patterns. Beal and Steward (2011) in South East Queensland or the residential end use studies conducted in the USA (Mayer et al., 1999 and DeOreo and Mayer, 2014) obtained updated information on single-family residential water use at a very detailed level. In Spain, Canal de Isabel II, a public utility that manages the integral water cycle in the Community of Madrid, analysed the most influential variables of consumption - occupation, number of toilets and the income level - and characterized the end uses of water of single-family and multi-family dwellings (Cubillo et al., 2008).

In general, results from these end use studies are consistent, though they show some differences that can be easily explained by cultural and sampling related factors. In table 1 average daily end uses breakdowns per household are shown. Due to the cultural and local factors mentioned before, and the geographical proximity, this study takes as the more applicable reference the Spanish end use breakdown obtained by Cubillo et al. (2008).

Table 1. Some examples for end use breakdowns in literature and internet.

\begin{tabular}{lcccccc} 
& $\begin{array}{c}\text { USA } \\
\text { REUWS1 } \\
(1999)\end{array}$ & $\begin{array}{c}\text { USA } \\
\text { REUWS2 } \\
(2014)\end{array}$ & $\begin{array}{c}\text { Beal and } \\
\text { Steward } \\
(2011)\end{array}$ & $\begin{array}{c}\text { Vewin } \\
(2016)\end{array}$ & $\begin{array}{c}\text { Loh } \\
\text { andCoghlan } \\
(2003)\end{array}$ & $\begin{array}{c}\text { Cubillo et } \\
\text { al multi- } \\
\text { family } \\
(2008)\end{array}$ \\
\cline { 2 - 7 } & $(\%)$ & $(\%)$ & $(\%)$ & $(\%)$ & $(\%)$ & $(\%)$ \\
\hline Toilet & 27 & 25 & 17.15 & 28.4 & 17 & 23 \\
Clothes washer & 22 & 17 & 22.43 & 12 & 26 & 11 \\
Shower & 17 & 20 & 30.90 & 43.2 & 33 & 27 \\
Dish washer & 1 & 1 & 1.81 & 1.7 & - & 1.1 \\
Tap /Faucet & 18 & 23 & 19.9 & 10.3 & 21 & 35 \\
Bathtub & 2 & 3 & 1.3 & 1.5 & - & - \\
Leaks & 14 & 13 & 6.51 & - & - & 3 \\
Other & - & - & - & 2.9 & 3 & -
\end{tabular}

\section{REDUCTION IN CONSUMPTION DUE TO NETWORK PRESSURE}

The Gipuzkoako Urak public utility requested a report on the effect of pressure management in water consumption and its potential economic impact on the water utility financial balance. In order to reach reliable conclusions, three requirements were set at the time of selecting the network where the case study could be conducted. Firstly, the existence of remote water meter reading infrastructure, so hourly readings could be available for a precise analysis on the variations of consumption with pressure. Secondly, the availability of a homogeneous water consumers' sample. Finally, the existence in part of the DMA of pressure reducing valves at the customers' connections, so there would be a control group for the study.

Remote water meter reading infrastructure is not yet widespread in Gipuzkoa (North of Spain) and the participating public utility had only three pilot DMAs with test equipment installed. From the three DMAs only one met all the established criteria: a residential sector in the touristic municipality of Getaria comprising 61 properties. Of these, 11 were non-residential (commercial offices) and 50 residential. Amongst these, 35 properties had their own pressure reducing valves at the connection supply line (this customers are identified as cust-PRV hereafter) and have been used as a control group to estimate the effect of seasonality. The PRVs installed at the customers' connections are 
simple direct action pressure reducing valves, and the setting of these valves was not changed during the study. The remaining customers of the DMA did not have a PRV installed at the connection line (these customers are identified as DMA-PRV hereafter) and their consumption was affected by the network pressure. This pressure was controlled by a pilot operated valve located at the inlet of the DMA installed before the pilot study started. Pilot operated PRVs provide an accurate and responsive pressure control, maintaining downstream pressure constant and always below the adjusted value. Pressure settings of the DMA PRV was changed three times during the study. The replacement of the simple direct action PRV installed at the customers's connection lines by the more complex and accurate pilot operated PRVs was not considered necessary nor feasible for the analysis conducted.

The housing morphology is homogeneous within the DMA, with three storey buildings of the same age, a built surface of approximately $110 \mathrm{~m}^{2} /$ household and 1 bathroom/ household. Therefore, although the total number of properties is not very large, the reliability and quantity of the data collected (462,624 hourly consumptions) by the remote reading equipment, allowed a high precision and consistency in the results.

Four consumption periods were subject to analysis: an initial period where the standard operating pressure of 7.35 bar was maintained at the inlet of the DMA, a second period where the pressure was reduced to 4.7 bar, a third period where pressure is returned to the original pressure of 7.35 bar $(\mathrm{P} 3=$ $\mathrm{P} 1)$ and, finally, a fourth period where the pressure is reduced again to 4.7 bar $(\mathrm{P} 4=\mathrm{P} 2)$. Table 2 shows the periods in which these pressure changes were made. The public utility staff was in charge of manipulating the PRV and the timing of these operations was adapted to the utility's circumstances.

Table 2. Periods timing.

\begin{tabular}{cccc}
\hline Period & $\begin{array}{c}\text { Pressure } \\
\text { (bar) }\end{array}$ & Start date & Finish date \\
\hline P1 & 7.35 & $01 / 09 / 2014$ & $22 / 04 / 2015$ \\
P2 & 4.70 & $22 / 04 / 2015$ & $14 / 07 / 2015$ \\
P3 & 7.35 & $14 / 07 / 2015$ & $28 / 09 / 2015$ \\
P4 & 4.70 & $28 / 09 / 2015$ & $18 / 10 / 2015$ \\
\hline
\end{tabular}

\section{Hourly consumption profile analysis}

The hourly consumption profile shows how water consumption changes throughout the day. Figure 1 describes the average hourly consumption profile of all customers before pressure reduction is implemented. Consumption peaks, at approximately 9:00 in the morning and 21:00 at night, confirm the main residential nature of the sector. The box plot presents the variability of the consumption measured per hour during the first period and shows the homogeneity of water consumption in the DMA under study and the small dispersion of the data collected. 


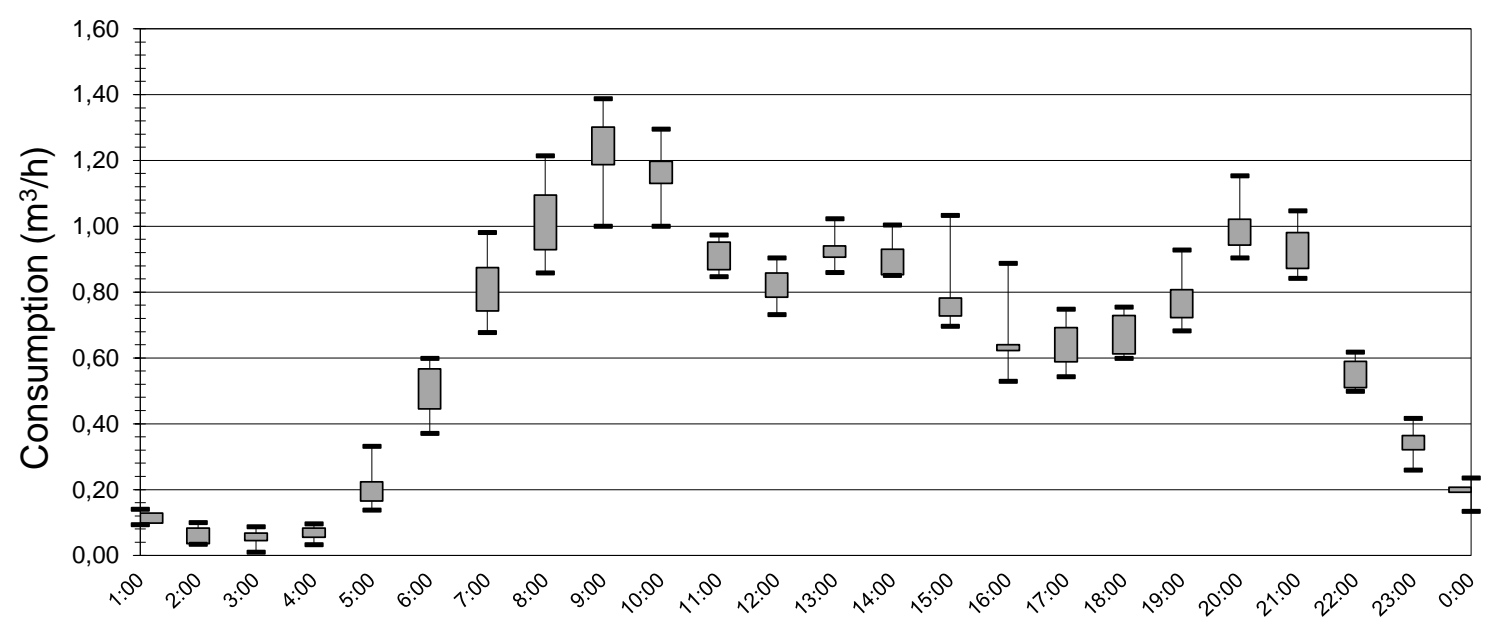

Figure 1: Average hourly consumption before pressure reduction

The hourly consumption profile in households with a PRV installed at their connection line (custPRV), maintains the shape and magnitude despite the reduction in network pressure. Figure 2 shows the average hourly consumption profile for these households during the first two periods of the study. Consumption peaks and the overall shape of the hourly consumption profiles are maintained and the differences between the first two monitoring periods are negligible. However, a very slight increase in consumption, accounting for less than $10 \%$, during the peak hours is detected. A probable cause for these minor differences can be found in seasonality.

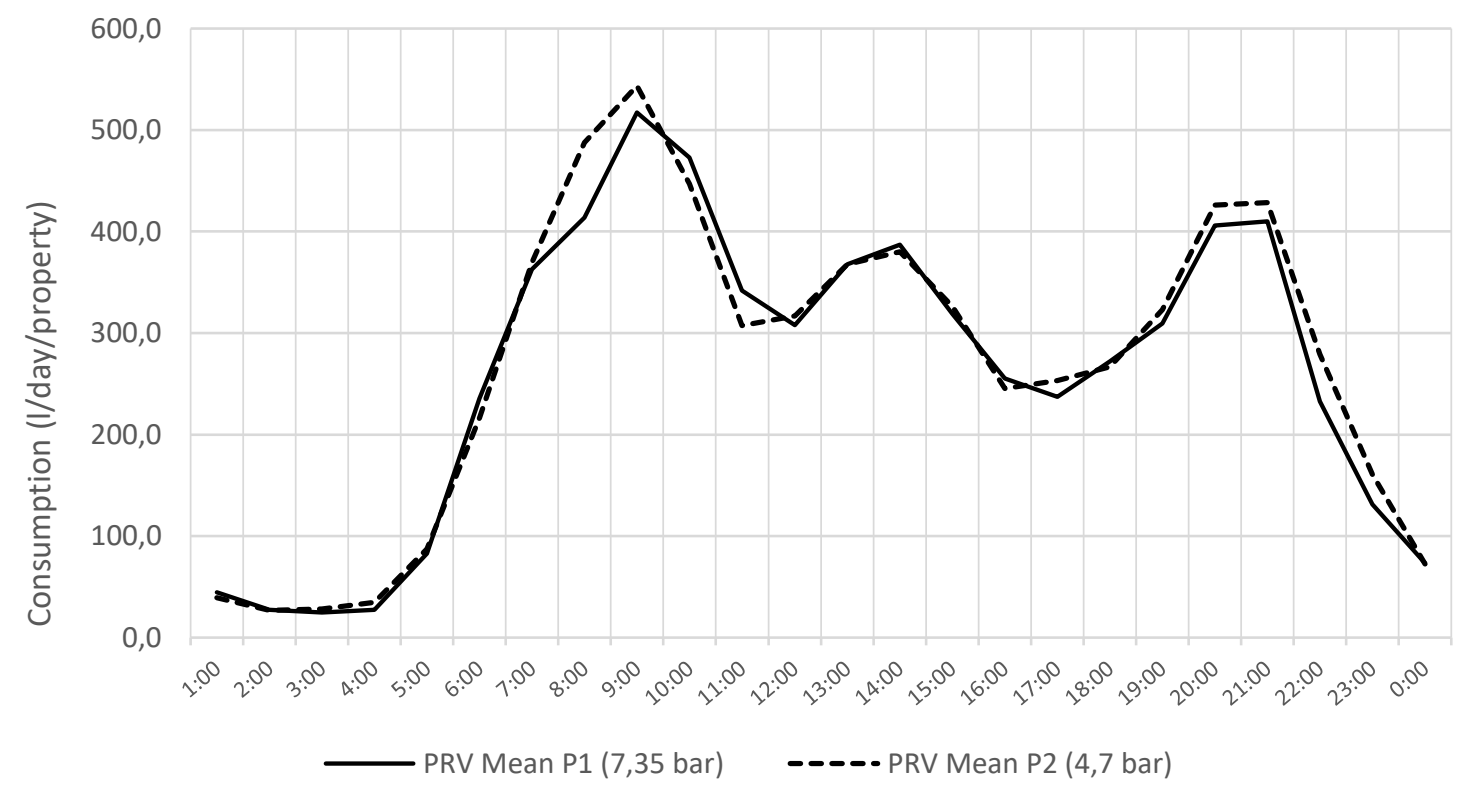

Figure 2: Average hourly consumption during P1 and P2 for Cust-PRV properties

Figure 3 shows a comparison of the hourly consumption profiles, for P1 and P2 periods, of households not having a PRV in their connection line (customers identified as DMA-PRV). Although the overall shape of the hourly consumption profile is maintained, there is a clear reduction in consumption from P1 to P2, when network pressure decreases from 7.45 bar to 4.7 bar. This drop in consumption is mainly observed during the central hours of the day and it is maintained throughout that period. Taking cust-PRV properties as a reference, the larger morning peak observed in Figure 3 can also be 
explained by the effect of seasonality.

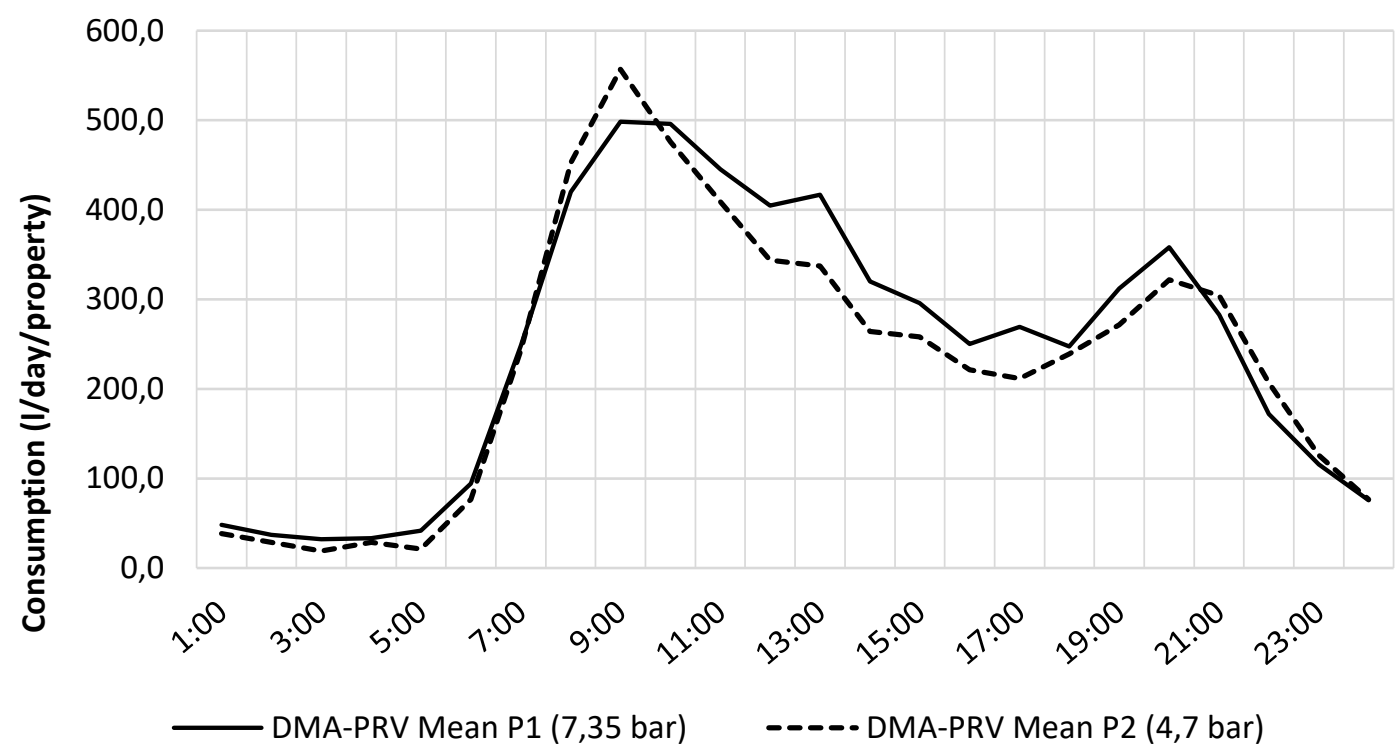

Figure 3: Average hourly consumption during P1 and P2 for DMA-PRV properties

The average monthly consumption of properties with its own PRV (cust-PRV) rises between periods $\mathrm{P} 1$ and P2 from 259.6 L/day to $276.9 \mathrm{~L} /$ day (Figure 2), that is, an increase of $6.6 \%$. Pressure at the consumption points in these hosueholds was not been affected by the pressure reduction in the network. In contrast, the average monthly consumption of households without a PRV at the connection line (DMA-PRV) decreases from 246.3 L/day to $241.8 \mathrm{~L} /$ day and property (figure 3), representing a decrease of $1.8 \%$. As the consumption conditions are the same for both customers types, cust-PRV and DMA-PRV, it is estimated that the actual decrease in consumption due to pressure reduction in the network is $8.4 \%(6.6 \%+1.8 \%)$.

\section{Analysis of seasonality}

In order to make a proper comparison between periods, water consumption seasonality of the selected customers has been examined in detail using billing data from 2016 (so water consumption is not affected by the variations in pressure of the study). The analysis shows that water consumption of these customers was affected by seasonality (Table 3). Seasonality correction coefficients were derived for each period and type of customer (DMA-PRV and cust_PRV) to account for these variations in consumption.

Table 3 shows the average measured daily consumption per customer type (DMA-PRV vs. cust-PRV) and period. This table also presents the consumption figures corrected with the seasonality coefficients obtained from 2016 billing data. DMA-PRV households, which are affected by network pressure reductions, show an average consumption change, seasonality corrected, from P1 to P2 of $-7.2 \%$, and from P3 to P4 of $-11.9 \%$. On the other hand, cust-PRV households, which are not affected by network pressure, show a corrected consumption change of $+0.6 \%$ from $\mathrm{P} 1$ to $\mathrm{P} 2$ and $-2.6 \%$ from $\mathrm{P} 3$ to $\mathrm{P} 4$. Therefore, pressure reduction from 7.35 bar to 4.7 bar between $\mathrm{P} 1$ and $\mathrm{P} 2$ reduces consumption by $7.8 \%(7.2 \%+0.6 \%)$ and from P3 to P4 the consumption decreases by $9.3 \%(11.9 \%$ $-2.6 \%)$. 
Table 3. Average daily consumption and consumption reductions per customer type

\begin{tabular}{|c|c|c|c|c|}
\hline & $\begin{array}{c}\text { Seasonality } \\
\text { coefficient }\end{array}$ & $\begin{array}{c}\text { Avg. daily } \\
\text { Consumption } \\
\left(\mathrm{m}^{3}\right)\end{array}$ & $\begin{array}{c}\text { Corrected } \\
\text { consumption } \\
\left(\mathrm{m}^{3}\right)\end{array}$ & $\begin{array}{c}\text { Reduction in } \\
\text { consumption }\end{array}$ \\
\hline DMA- VRP & & & & \\
\hline P1 (7.5 bar) & 0,96 & 4,7 & 4,9 & \\
\hline P2 (4.7 bar) & 0,99 & 4,5 & 4,5 & $\mathbf{- 7 , 2 \%}$ \\
\hline P3 (7.5 bar) & 1,088 & 5,4 & 5,0 & \\
\hline P4 (4.7 bar) & 1,029 & 4,5 & 4,4 & $\mathbf{- 1 1 , 9 \%}$ \\
\hline Cust-VRP & & & & \\
\hline P1 (7.5 bar) & 0,98 & 10,7 & 10,9 & \\
\hline P2 (4.7 bar) & 1,02 & 11,2 & 11,0 & $\mathbf{0 , 6 \%}$ \\
\hline P3 (7.5 bar) & 1,06 & 12,8 & 12,1 & \\
\hline P4 (4.7 bar) & 1,02 & 12 & 11,8 & $\mathbf{- 2 , 6 \%}$ \\
\hline
\end{tabular}

\section{WATER DEMAND COMPONENTS}

The N3 coefficient can be estimated considering the end use breakdown obtained in Spain for multyfamily housing (Cubillo et al., 2008). Accounting that pressure management will only affect pressure dependent uses, pressure dependent and independent water uses are disaggregated according to the following assumptions:

- Pressure independent or volume-based domestic uses are considered to be toilet cisterns, dishwashers and washing machines. These uses represent 35\% (23\%, $1 \%$ and $11 \%$ respectively) of daily average domestic consumption.

- Pressure dependent or human-based consumptions are showers and leaks, representing 30\% (27\% and $3 \%$ respectively) of daily average domestic consumption.

- Tap consumption (35\%) cannot be considered fully pressure dependent or independent, as it is greatly influenced by the usage given to this water.

Thus, three possible scenarios were studied: E1 where $100 \%$ of tap consumption is accounted as a pressure dependent use, E2 where tap consumption is equally distributed between pressure dependent and independent uses, and E3 where all tap consumption is considered to be pressure independent (see Table 4).

$\underline{\text { Table 4. Scenarios for domestic water consumption pressure dependancy }}$

\begin{tabular}{ccccccc}
\hline Scenario & \multicolumn{3}{c}{ Independent (\%) } & \multicolumn{3}{c}{ Dependent (\%) } \\
\cline { 2 - 6 } & $\begin{array}{c}\text { Always } \\
\text { independent } \\
\text { uses }(\%)\end{array}$ & $\begin{array}{c}\text { Tap } \\
\text { considered } \\
\text { independent } \\
(\%)\end{array}$ & $\begin{array}{c}\text { Total } \\
\text { pressure } \\
\text { independent } \\
\text { uses (\%) }\end{array}$ & $\begin{array}{c}\text { Always } \\
\text { pressure } \\
\text { dependent } \\
\text { uses }(\%)\end{array}$ & $\begin{array}{c}\text { Tap } \\
\text { considered } \\
\text { pressure } \\
\text { dependent } \\
(\%)\end{array}$ & $\begin{array}{c}\text { Total } \\
\text { pressure } \\
\text { dependent } \\
\text { uses }(\%)\end{array}$ \\
\hline E1 & 35 & 0 & $\mathbf{3 5}$ & 30 & 35 & $\mathbf{6 5}$ \\
E2 & 35 & 17.5 & $\mathbf{5 2 . 5}$ & 30 & 17.5 & $\mathbf{4 7 . 5}$ \\
E3 & 35 & 35 & $\mathbf{7 0}$ & 30 & 0 & $\mathbf{3 0}$
\end{tabular}


Applying the Torricelli law (that is $\mathrm{N} 3=0.5$ ) and assuming that all consumption is pressure dependent, a pressure reduction of $1 \%$ would imply a reduction of the flow rate of $0.5 \%$. In the present study, the pressure reduction starts at an initial value of 7.35 bar and is lowered to 4.7 bar, which means a reduction of $36 \%$ on the original pressure. If all consumption in the network was pressure dependent, this reduction would lead to a $18 \%$ reduction in consumption (Figure 5).

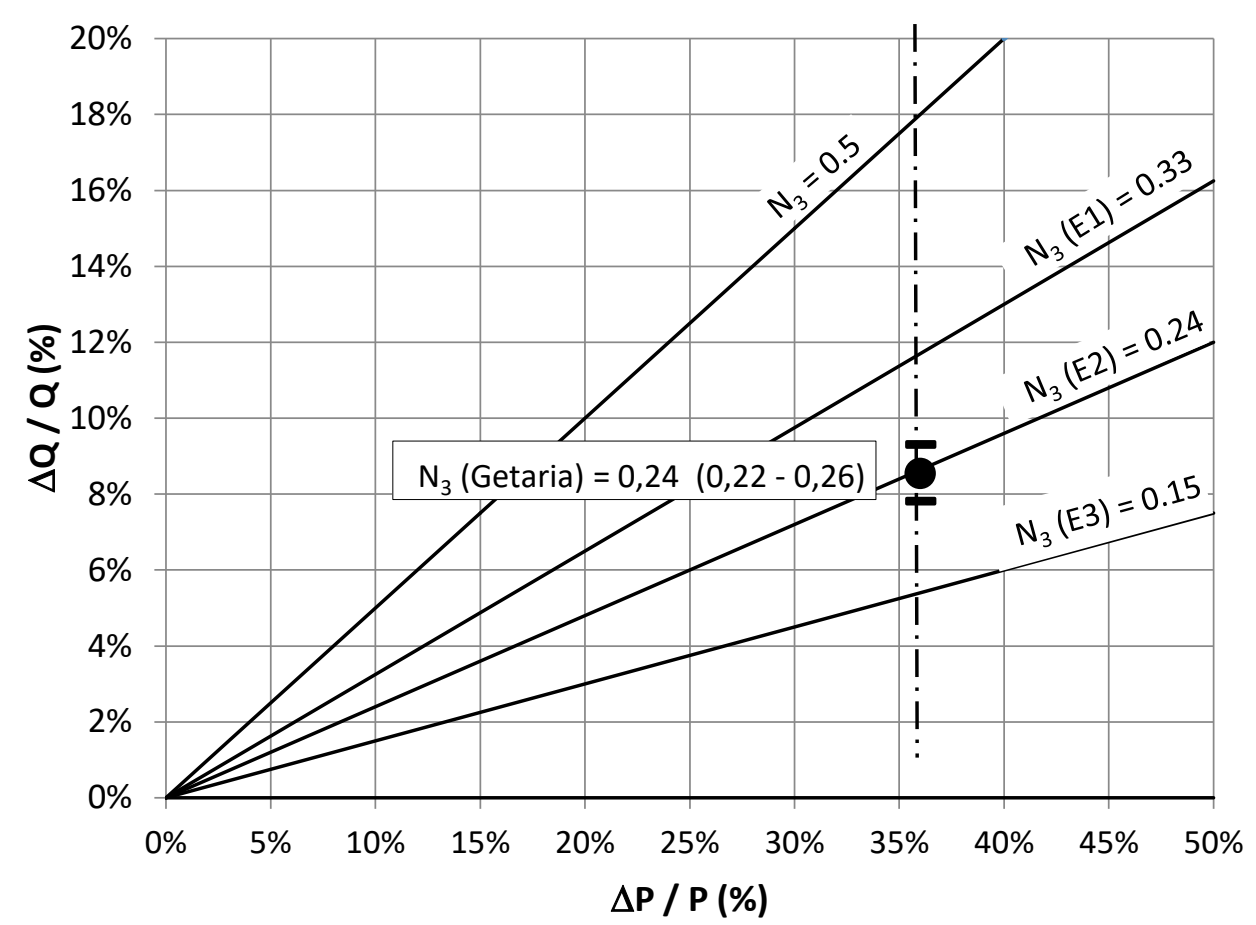

Figure 5: Influence of pressure in residential consumption

However, it has been assumed that the amount of volume consumed by pressure independent uses remain constant and therefore do not contribute to a reduction in consumption. Thus, the decrease of $18 \%$ in consumption is only applicable to pressure dependent components $(65 \%$ in E1, $47.5 \%$ in E2 and $30 \%$ in E3). With this distribution, the expected consumption reduction would range from 5\% to $12 \%$ for the three scenarios considered (11.7\% for E1, 8.5\% for E2 and 5.4\% for E3). Therefore, the resulting N3 coefficients are 0.33 for E1, 0.24 for E2 and 0.15 for E3. This is fully consistent with the results obtained experimentally in Getaria where consumption is reduced by $7.8 \%$ (from P1 to $\mathrm{P} 2$ ) and $9.3 \%$ (from $\mathrm{P} 3$ to $\mathrm{P} 4$ ). $\mathrm{N} 3$ coefficients are respectively 0.22 and 0.26 , indicating that around $50 \%$ of tap consumption is pressure dependent, that is, a N3 coefficient of 0.24 (Figure 5).

\section{CONCLUSIONS}

Reducing pressure in distribution networks has numerous advantages such as lowering leakage rates and burst frequency and increasing the theoretical longevity of pipes. In addition there are also environmental and social benefits deriving from minimising the extraction of water from the natural environment. Although it is commonly accepted that pressure management will also reduce consumption, there are few studies regarding this relationship. This paper aims to contribute to the existing literature establishing for the case of Spain a range of feasible N3 coefficients.

A multi-family residential sector equipped with remote water meter reading was selected to be 
monitored as pressure were reduced. This analysis showed a reduction in consumption between $9.3 \%$ and $7.8 \%$ in two different periods, subjected to the same pressure reduction of $36 \%$ (from 7.35 bar to 4.7 bar). This reduction in consumption implies a N3 coefficient ranging from 0.22 to 0.26 Results are consistent with the theory that human-based consumption is partially non-volumetric (Giustolisi and Walski, 2012).

The experimental values were compared with estimations of N3 coefficients from an end use study for the Community of Madrid based on three possible scenarios for tap consumption pressure dependency. Here the N3 coefficient ranged from 0.15 to 0.33 . The experimental values for N3 fall within the theoretical Madrid range. Specifically, results determine that tap consumption is around $50 \%$ pressure dependent.

Nonetheless, values extracted or estimated from literature vary significantly. This might be due to these few studies found on consumption reduction being related to single-family housing with significant contribution of outdoor consumption. The authors consider that although this study represents an attempt to create a comprehensive framework for consumption reduction with pressure management, there is a need for additional research based on data from actual users to analyze the sensitivity of the N3 coefficient to end use estimations and identify the proportion of pressure dependency of indoor consumption.

\section{REFERENCES}

Almandoz, J., Cabrera, E., Arregui, F., Cabrera Jr, E., and Cobacho, R. 2005 Leakage assessment through water distribution network simulation. Journal of water resources planning and management. 131(6), 458-466.

Bamezai, A., and Lessick, D. 2003 Pressure optimization to reduce residential water consumption, 2003 AWWA Annual Conference.

Beal, C.D. and Stewart, R.A. 2011 South East Queensland Residential End Use Study: Final Report. Urban Water Security Research Alliance Technical Report No. 47.

Cubillo, Moreno and Ortega 2008 Microcomponentes y factores explicativos del consumo doméstico de agua en la Comunidad de Madrid, Cuadernos de I+D+I, 4, Canal de Isabel II, Madrid.

DeOreo, W. B. and Mayer, P.W. 2014 Residential end uses of water study update. Water Research Foundation, Denver.

Giustolisi, O., and Walski, T. M. 2012 Demand components in water distribution network analysis. Journal of Water Resources Planning and Management. 138(4), 356-367.

GIZ 2011 Guidelines for water loss reduction. A focus on pressure management. Eschborn, Germany.

Gomes, R., Sa Marques, A., and Sousa, J. 2011 Estimation of the benefits yielded by pressure management in water distribution systems. Urban Water Journal. 8(2), 65-77.

Lambert, A. 2001 What do we know about pressure-leakage relationships in distribution systems. In IWA Conf. $n$ Systems approach to leakage control and water distribution system management. 
Lambert, A. O., and Fantozzi, M. 2010 Some Examples of European Water Loss Targets, and the Law of Unintended Consequences. IWA Specialised Conference 'Water Loss 2010', Sao Paolo, Brazil, June 2010

Loh, M.; Coghlan, P. 2003 Domestic Water Use Study in Perth, Western Australia 1998-2001 Water Corporation, Australia, 1-33.

May, J. 1994 Pressure dependent leakage. World water and environmental engineering. 17(8), 10.

Mayer, P.W., DeOreo, W. B., Opitz, E.M., Kiefer, J.C., Davis, W.Y., Dziegielewski, B. and Nelson, J.O. 1999 Residential End Uses of Water AWWA Research Foundation and American Water Works Association, Denver.

Cubillo, F., Moreno, T. and Ortega, S. 2008 Microcomponentes y factores explicativos del consumo doméstico de agua en la Comunidad de Madrid. Cuadernos de I+D+I, Isabel II, Madrid.

Shan, Y., Yang, L., Perren, K. and Zhang, Y. 2015 Household water consumption: insight from a survey in Greece and Poland. 119, 1409-1418.

Thornton, J., and Lambert, A. 2005 Progress in practical prediction of pressure: leakage, pressure: burst frequency and pressure: consumption relationships. In Proceedings of IWA Special Conference'Leakage .

VEWIN, 2016

http://www.vewin.nl/SiteCollectionDocuments/Publicaties/Vewin Drinking water faC $t$ sheet 2016.pdf

Vicente, D. J., Garrote, L., Sánchez, R., and Santillán, D. 2015 Pressure Management in Water Distribution Systems: Current Status, Proposals, and Future Trends. Journal of Water Resources Planning and Management. 142(2), 04015061.

Willis, R.M., Stewart, R.A., Giurco, D.P., Talebpour, M.R., Mousavinejad, A. 2013 End use water consumption in households: impact of socio-demographic factors and efficient devices. Journal of Cleaner Production. 60, 107-115. 